This is the accepted author manuscript.

The version of record of this manuscript has been published and is available: Rita Basílio Simões \& Maria João Silveirinha (2019) Framing street harassment: legal developments and popular misogyny in social media, Feminist Media

Studies, DOI: $\underline{\text { 10.1080/14680777.2019.1704816 }}$

\title{
Framing street harassment: legal developments and popular misogyny in social media
}

Rita Basílio de Simões*

Department of Philosophy, Communication and Information, Faculty of Letters of the University of Coimbra, Coimbra, Portugal

ORCID ID: https://orcid.org/0000-0001-6356-6042

Maria João Silveirinha

Department of Philosophy, Communication and Information, Faculty of Letters of the University of Coimbra, Coimbra, Portugal

ORCID: https://orcid.org/0000-0002-0702-

3366

* Corresponding author

Address: Departamento de Filosofia, Comunicação e Informação da Faculdade de Letras da Universidade de Coimbra Largo da Porta Férrea 3004-530 Coimbra Portugal E-mail: $\underline{\text { rbasilio@fl.uc.pt }}$

Rita Basilio de Simões holds a PhD in Communication Sciences, with a thesis on Crime, punishment and gender. She is Assistant Professor at the University of Coimbra, Portugal, at the Department of Philosophy, Communication and Information, where she teaches Journalism and Communication Sciences. Her main research areas include journalism and media with a focus on feminist studies, social representations of violence, crime and criminal justice with an emphasis on gender, and the regulation of media and journalism.

Maria João Silveirinha is Associate Professor at the University of Coimbra, Portugal, at the Department of Philosophy, Communication and Information. She holds a PhD in Communication Sciences from the Universidade Nova de Lisboa. Her research interests are on the issue of relationship between identities and communication with a focus on feminist media studies, communicative rights of women, their media representations and political and social aspects of the media public sphere. She is currently vice-president of the Portuguese Women's Studies Association. 


\title{
Framing street harassment: legal developments and popular misogyny in social media
}

\begin{abstract}
In September 2015, following the ratification of Istanbul Convention by Portugal, addressing someone with unwanted verbal "sexual proposals" became a criminal offence. This however, barely meets the requirements of the treaty and is far from what was first discussed about sexual harassment both in the Portuguese Parliament and more broadly in the media. When the criminalization of "piropo" - the Portuguese colloquial word for "catcalling" - was first proposed, it sparked heated opposition in online discussions, revealing strong prejudices against women and anti-feminist sentiments. Aiming to contribute to the understudied area of street harassment, this article maps the ways in which its legal developments were framed and counter-framed between August 2013 and September 2018, corresponding to the period before, during and after its adoption. Methodologically, we worked through the combination of quantitative and interpretative methods in order to understand gender politics in public policy making, through the study of news media texts and readers' comments posted on Facebook. We argue that whereas feminist interpretations found their way into media texts, reader's discussions expressed the popular misogyny that shaped the law reform.
\end{abstract}

Keywords: Street harassment; violence against women; frame analysis; Feminist Critical Discourse Analysis; misogyny

\section{Introduction}

Following the ratification of Istanbul Convention by Portugal, in September 2015, the 38th amendment to the Portuguese Penal Code came into force, as introduced 
by Law N. 83/2015. Article 170 of the Penal Code (pertaining to "Importunação sexual") was amended in order to include some forms of sexual verbal abuse, in addition to other legal interventions required by the Convention. The law now states that practicing exhibitionist acts, forcing a contact of a sexual nature, or verbalising proposals of sexual nature is punishable by a prison sentence of up to a year, or a penalty fine.

Whereas "workplace sexual harassment" was already qualified in Portuguese Labour Law as a serious offense, some types of street harassment thus became criminalized, finally meeting some of the claims of Portuguese feminist scholars (Maria José Magalhães 2011; Clara Sottomayor 2015) and associations, such as UMAR Union of Women Alternative and Response. Tandem with the redefinition of legal boundaries, this almost invisible and understudied (Laura Logan 2015; Fiona Vera-Gray 2016) branch of the feminist project on violence against women, particularly in Portugal (Magalhães 2011, 103), found a space for being acknowledged. But this was highly contested, and the law did not go as far as many feminists advocated to end all forms of street harassment.

To understand how the law came about, we can go back to 2014 when the Istanbul Convention launched a set of legally compulsory obligations to ensure a "holistic" response to all forms of violence against women, including sexual harassment. The treaty sees violence against women as encompassing a range of experiences, from intimate partner violence to sexual violence, and defines "sexual harassment" as any type of unwanted behaviour of a sexual nature, in verbal, non-verbal or physical form, with the purpose or effect of violating a person's dignity, particularly when it creates an intimidating, hostile, degrading, humiliating or offensive environment (art. 40). All forms of violence against women are classified not only as 
harms that beg for a legal sanction, but as behaviours of a gendered nature, a key insight of feminist research and activism, present in several United Nations nuclear documents, namely the Declaration on the Elimination of Violence against Women, adopted in 1993. Feminists see violence against women as part of a permissive sexist culture that normalizes male aggression (Elisabeth Stanko 1985; Liz Kelly 1988; Russell Dobash and Emerson Dobash 1992) and makes up a "continuum" of violence (Kelly 2012), from acts of intimidation to major life-threatening behaviours of physical and sexual violence.

Emphasising that local context, cultural backgrounds and feminist projects on violence against women have to be studied together, we now briefly look at the country's historical and cultural environment that shapes people's beliefs, attitudes, and behaviours in gender terms.

\section{Setting the scene: gender relations, (popular)feminism, and misogyny}

Gender relations in Portugal derive from a long history of an authoritarian political system that ruled the country for half the twentieth century, alongside the strong influence of the Catholic Church. Much has changed since democracy came to the country in 1974, but undoubtedly one of them is women's awareness regarding the inequality they had traditionally been subject to in society. Feminists who began to undermine patriarchal principles in the 70s and 80s found allies in the state and with the help of state feminism, laws were updated, creating a much more favourable country for women.

Yet, despite the current emphasis of public polices of equality measures, much remains to change in the cultural environment. Rosa Monteiro and Virgínia Ferreira $(2016,1)$ note that "the remarkable legal framework nevertheless contrasts with the 
disjunction that exists between legal and political formalism and the de facto social situation". More broadly, Aboim and Vasconcelos $(2012,3)$ point out that: "The principles of gender equality, and of overall equality between all individuals, are very rarely openly questioned in the Portuguese public sphere, even by conservative organizations, such as the Roman Catholic Church. The trauma of the dictatorship and its strongly traditionalistic agenda is still well alive".

A clear symptom of how the relations between the sexes are generally understood is the judicial field. In 2017, women's rights groups were angered by a court decision that quoted the Bible and a 19th-century law in justifying a suspended sentence for a man convicted of assaulting his ex-wife with a bat because she allegedly committed adultery ${ }^{1}$. Rulings such as these establish not only the broad understandings of much of the national culture of gender relations, but a particularly misogynist attitude that still characterizes Portuguese society. Machismo also looms in high levels of violence against women.

In the other hand, as in many western countries, feminism is also now a popular word in the national public sphere, in news articles, t-shirts, advertising and social media, where signs of postfeminist sensibilities (Rosalind Gill 2007) can be observed. But with this popularity came another one, as the old entrenched misogyny became more assumed, more unapologetic and more naturalized, as seen in many online and networked spaces (Sarah Banet-Weiser 2018).

The contradictions and complex intertwining of old and new feminist sensibilities as well as old and new misogyny can be observed around specific pulls and

\footnotetext{
${ }^{1}$ See, for example, Euronews, 23/10/2017 "Portuguese judge uses Bible to excuse abusive husband". https://www.euronews.com/2017/10/23/portuguese-judge-sparks-row-with-use-of-bible-to-defenddomestic-violence
} 
pushes on the media environment set in motion by the adoption of public policies and laws concerning the relations of men and women, as discussed below.

\section{Street harassment laws in the Portuguese context}

The first national steps to make street harassment illegal go back to September 2013 when the left-wing political party Bloco de Esquerda advocated the criminalization of the offensive "piropo" - the Portuguese colloquial word for "catcalling" - in a Conference aiming to discuss the issue ${ }^{2}$. News about this conference sparked fierce opposition in the mediated public sphere. It was also again highly disputed one year later when Bloco de Esquerda took the discussion of verbal assault to Parliament, hoping to criminalize "sexual harassment".

As feminist knowledge on street harassment gained public awareness it also backlashed in anti-feminist sentiments, sexism and aggressive anti-feminist expressions. This was indeed an expression of "popular misogyny" as discussed above, understood not as solely an anti-feminist backlash, but as a "normative reaction" to feminist constructions circulating overtly in the public sphere (Banet-Weiser 2018; Gill 2016; Jessalynn Keller, Kaitlynn Mendes, and Jessica Ringrose 2018).

Unsurprisingly, the issue was quietly resolved by the Parliament's majority in 2015 by amending an already existing crime. Although some limited forms of harassment were included in the previous version of the law, it was restrictive to exhibitionist behaviours and sex-related contacts. In the new amended law, the criminal harm goes beyond this and includes threatening and intrusive comments, but only if in the form of a "sexual proposal". This means that there is still no specific streetharassment legislation that would create more targeted provisions to address and

\footnotetext{
2 "Engole o teu piropo", Fórum Socialismo 2013.
} 
acknowledge the abuse that women and girls disproportionately face in public spaces. Thus, numerous offensive words or sounds addressed to passing by women and girls as well as several hurtful acts such as gross facial expressions and hand movements, may not fit the legal provisions. Only behaviours that include verbal "sexual proposals" are considered criminal offenses. This led the independent Group of Experts on Action against Violence against Women and Domestic Violence (GREVIO) monitoring the implementation of the Istanbul Convention, to consider that this definition "falls short of the aim" of the Treaty, because it does not "capture a pattern of behaviour whose individual elements, if taken on their own, may not necessarily result in a sanction" (GREVIO 2019, 49).

The reactions to the amendments were clearly seen in the mediated public sphere, becoming ideal moments to study how the problem of street harassment is repeatedly downplayed and victims ridiculed by a culture that feminists fight hard to change in order to produce a cultural shift in the normalisation and widespread acceptability of street harassment. Thus, bearing in mind these gaps of the legislative change, in the remaining sections of this article, we map the ways in which the legal developments on street harassment were framed and counter-framed between August 2013 and September 2018. This time-frame grasps the first relevant public initiative to create awareness regarding street harassment, in September 2013, the law's amendment coming into force in in September 2015, and the discussion about harassment from the influence of the \#Me Too movement. Countering the dearth of empirical studies on this key social issue, we worked through the combination of quantitative and qualitative methods, frame analysis and feminist critical discourse analysis, to search for the meanings found on media texts and readers' comments posted on Facebook. This is the platform where most Portuguese media outlets post their content to be commented on, 
and where feminist activism has gained visibility. We aim to know: What were the main frames of mainstream and alternative feminist media texts and their readers' comments? How do these frames relate to sociocultural gender constructions and to male and female online identities? To what extent was the issue des/legitimized, helping to shape the wider socio-political context?

To answer these questions, we follow previous work by other researchers on traditional media outlets (Olatokunbo Olukemi Laniya 2005) and on digital media (Bianca Fileborn 2014, 2016a; Benjamin Bailey 2017).

We begin with a discussion of street harassment and a description of the background of the media debates surrounding the legal developments of the issue in Portugal. We then present the methodological framework, including the research procedures and methods. Lastly, we discuss the main results, establishing a link between the misogynist media environment and the limited legal accomplishments of the law in dealing with the issue of street harassment.

\section{Tackling Street harassment}

The experiences of harassment in public spaces were originally part of feminist analyses of 1980s and early 1990s, concerned with the unpunished and yet everyday presence of this form of violence against women (Carol Brooks Gardner 1980 1995; Kelly 1988; Stanko 1985; Davis Deirdre 1994; Cynthia Grant Bowman 1993). Scholars and activists claimed that harassment experiences should be recognized as harms that violate women's integrity, autonomy and freedom, which are one the "continuum of violence against women" (Kelly 1988) that perpetuates women's female subordination. Whether understood as "genderizing" the street (Deirdre 1994) or creating an "informal 
ghettoization of women" (Bowman 1993), street harassment was conceptualized as distributing power in a way that reifies patriarchal culture.

Despite these early efforts, concerns with street harassment fell off the academic radar in the following years, rarely being acknowledged as a legitimate area of study (Logan 2015; Vera-Gray 2016). Recent research indicates that the gender-gap is even greater in the case of street harassment (FRA 2014; Sottomayor 2015, 116). According to the first survey on violence against women across the European Union's (EU) 28 Member States, every second woman in the EU has experienced sexual harassment at least once since the age of $15(55 \%)$ (FRA 2014, 95). On the other, the main concern with harassment was always been more largely centred on the workplace, where it has been understood as encompassing "sexual hostility", "sexist hostility", unwanted sexual attention, and sexual coercion (Anne M. O'Leary-Kelly, Lynn Bowes-Sperry, Collette Arens Bates and Emily R. Lean 2009). Even after the "Me Too" movement, harassment continues to be more focused as a harmful workplace practice (Fiona Vera-Gray and Bianca Fileborn 2018). Yet, street harassment constrains women's presence in public spaces, as far as women think about harassment, fear it, and plan for it, even in its absence (Megha Dhillon and Suparna Bakaya 2014; Fileborn 2016a, 2016b, 2019; Holly Kearl 2015; Logan 2015).

The lack of attention devoted to street harassment may also be explained by the sociocultural constructions on gender and heterosexuality and the tension they cause between its definitions and perceptions. While women are socialized to dismiss, trivialized and maintain the experience of harassment as a private matter, men who harass act in accordance with the rooted social normativity (Isabel Dias 2008). Thus, being honked, wolf-whistled, catcalled and subjected to more physical forms of harassment, such as being stalked, groped and grabbed or having the path blocked, have 
been historically seen as normalized (Bowman 1993), as part of an "everyday sexism"(Laura Bates 2014), as harmless (Molly Johnson and Ebony Bennet 2015) or as expressions of free speech or a minor nuisance (Fileborn and Vera-Gray 2017).

As elsewhere, in Portugal, women have themselves got used to experience it as part of their everyday lives, with consequences on its underreporting and impunity (Dias 2008; Magalhães 2011; Sottomayor 2015). In the Violence Against Women National Survey in 1995, nearly one third of women over 18 admitted having been victim of at least one act of sexual violence in the last or in previous years (Nelson Lourenço, Manuel Lisboa and Elza Pais 1997). A similar result can be found in the 2007 National Gender Violence Survey, which further identifies "obscenities with the aim of harassing" as the most prevalent acts of sexual violence, committed mostly by men (Manuel Lisboa, Zélia Barroso, Joana Patrício and Alexandra Leandro 2009, 42-43). Yet, the perceptions of street harassment are linked to spread misunderstandings of female and male identity, as revealed by one of the rare Portuguese studies focusing the issue from a qualitative perspective. UMAR found the use of problematic discursive dimensions to define sexual harassment, namely, the women discursive construction as the "property of men" or as "invaders of the male public space" and the issue definition as a result of uncontrollable sexual impulses and/or the blaming of the victim (UMAR 2011, 64-66).

Since Bloco de Esquerda first brought the issue to the fore, competing evaluations of street harassment emerged, capturing the news media attention. This media attention had four key moments: 1) the public acknowledging of "piropo" as a criminal harm, in September 2013; 2) the proposal of criminalization of sexual harassment, in September 2014; 3) the Parliament's adoption of amendments to the existing law, in August 2015, that took effect the following month; and 4) the spread of 
the \#MeToo movement, after October 2017 The first two moments were met with intense online discussions receiving fierce public opposition. The third moment did not lead to as much media discussions, but the issue captured a renewed attention in 2017 , after the first signs of the \#MeToo movement, which brought sexual harassment into the open Together, these moments show the struggle over meaning of street harassment, highlighting cultural meanings of gender and its implications for change.

\section{Methodological framework and research design}

\section{Framing as media discourse: a feminist critical approach}

Framing has been a particularly important perspective for the analysis of the role of the media in social and political life. There are, however, many approaches to framing (Robert Entman 1993). For our own purposes, we found the insights by Baldwin Van Gorp (2005, 2007, 2010) and by Renée Moernaut, Jelle Mast and Luc Pauwels (2018) to be quite helpful. Van Gorp's $(2005,2007,2010)$ constructionist methodology allows us to build a "frame matrix" based on two key elements: frame packages and reasoning devices. A package "consists of all indicators or framing devices by which the frame can be identified: metaphors, catchphrases, visual images, lexical choices, selection of sources, graphics, stereotypes, dramatic characters, etc." (2005, 486). Reasoning devices are identified through answering the four framing functions referred to by Entman (2003): the promotion of a particular problem definition, causal interpretation, moral evaluation, and/or treatment recommendation".

Moernaut, Mast and Pauwels (2018) also argue that because it mostly puts emphasis on the surface structure of the communicative text - what is included and excluded, for example -, framing theory may not give the entire picture of how 
communicative power is established and contested. Thus, frames can justify dominant ideologies, although an ideology cannot be reduced to a frame. For that reason, they (217) describe three interconnected framing levels: 1) the level of the masterframes, corresponding to ideology, i. e., "broad collectives of language, images and ideas about how the world is and should be"; 2) the level of the frames, which help to organize in a certain way particular problems or concerns; and 3) the level of the subframes, which are shaped by the "immanent masterframes" on which they depend. So, each framesubframe package establish different sites of ideological battles.

With this in mind, and to advance the interpretation of frames in gender terms, we connected the frames identified to the gender ideologies implicated in the discursive representations of street harassment. In order to do that, we performed a Feminist Critical Discourse Analysis, understood as a method and a "political perspective which investigates the complex and diverse ways by which gender ideologies that entrench power asymmetries become «common sense» in particular communities and discourse contexts, and how they may be challenged" (Michelle Lazar 2018, 372). The identification of framing packages and devices allowed us to establish how the perceived reality of street harassment was defined; at the same time, feminist critical discourse analysis helped us to connect those framing packages and devices to power relations and gender ideologies in the discursive representations of harassment.

\section{Research procedures and methods}

We focused on Facebook as the platform where most media outlets post their news so that they can be commented on. Facebook is, in Portugal, the most popular platform for individuals to get their news (ERC 2016) and a place where citizens are not only exposed to different reports and opinions, but also one where they can express their 
own views on issues of the day. In addition, the growing scholarly interest in digital activism has been showing how online social networks can open spaces to discuss gender inequalities, fight against violence and structural sexism (Mara Magalhães, Lidia Moropo and Inês Amaral 2018; Karen Desborough 2018), and even “connect a wider feminist community" (Keller, Mendes and Ringrose 2018, 33). So, although we are aware of the "toxic talk" and online incivility (Ashley Anderson, Sara Yeo, Dominique Brossard, Dietram Scheufele, and Michael Xenos 2016), this is nonetheless where we can observe different framing interactions sparked by traditional media outlets and activists' communicative practices coming together around the issue of street harassment.

Research proceeded in three stages and used mixed methods (John Creswell and Vicki Plano Clark 2017), combining and integrating qualitative and quantitative analyses. First, we collected all the items (both news and opinion texts) about street harassment posted on three main national newspaper's Facebook Pages - Público, Correio da Manhã and Diário de Notícias - and on the most popular feminist organization Facebook page - Capazes. ${ }^{3}$ We searched for the posts containing the terms "piropo" and "street harassment", posted between August twenty thirteen and September twenty eighteen, the period encompassing the legal boundaries discussions. After filtering out unrelated texts we ended up with 49 articles. In a second stage, we collected all the reader's comments posted to each of the retrieved content. This amounted to a total of 1.759 posts (first level comments). Overall, the comments ranged from a few words to a large sentence or extended paragraphs.

\footnotetext{
${ }^{3}$ Capazes, whose founding activists are Portuguese national media celebrities, was first created in December 2014, under the name Maria Capaz. Given the absence or the low popularity on Facebook of other feminist organizations, we chose Capazes's Facebook page, which publications only started in late 2015. In March 2016, it had about 145.000 followers.
} 
We finally used a combination of quantitative and qualitative methods to examine and interpret the sample. Each media text was coded for title and source, author's gender and number of comments it generated. Comments were coded for the author's gender only, by analysing the online identity profiles (the name and the image of the commentator exhibited). Following the conceptual proposal of Moernaut, Mast and Pauwels (2018), an inductive-deductive qualitative analysis was then conducted. The sample were searched for the interconnected framing levels described by these authors. By coding rhetorical devices and other key resources of feminist critical discourse analysis to study social actors and their actions, we established a set of frame packages and the reasoning they allow. About one third of the retrieved texts and comments was subjected to this process of open coding frames (and subframes), to create a frame matrix. Whenever deviations from initial frames were repeatedly found, the frame matrix was updated. The remaining items were coded once the matrix was stabilized. Nearly half of the media texts and comments were coded independently by the authors and two research assistants in order to ensure consistency.

\section{Results and discussion}

The analysis of news/opinion articles and reader's comments produced a matrix of four frames and nine subframes, as shown in Figure 1.

\section{[Figure 1: Near here]}

This matrix represents a cognitive map of the meanings of street harassment legal developments as they were negotiated in Facebook interactions. Each frame structures the issue in a particular way. 
The Non-issue frame constructs street harassment as harmless and an irrelevant topic for public policy, either by disqualifying the issue itself or through the disqualification of its claimants; the Legal challenge frame presents the problem differently - as a technical-legal issue -, sometimes presenting it as a sign of social reform, but mostly as a backsliding or as an issue in need of clarification; the Individual deviant behaviour frame constructs street harassment as a reflection of the conduct of deviant men/women, occasionally reifying a victim-blaming perspective or stressing the parity in violence; finally, the Systemic deviant behaviour constructs street harassment as a systematic problem, situated in the context of broader issues concerning gender inequality or non-gender systemic experiences. Taken together, these frames operate three broad ideological operations as described below.

\section{Contradictory views and ambiguities}

Two frames dominated the mainstream and alternative media texts: Systemic deviant behaviour and Legal challenge, as shown by Table 1.

\section{[Table 1: Near here]}

The majority of the 49 media texts framed street harassment as Systemic deviant behaviour $(61,21 \%)$. Unsurprisingly, more than two-thirds of the texts published by the feminist platform Capazes constructs street sexual harassment as a recurring practice, inseparable from a problematic public space culture. Mainstream newspapers also largely view the issue as a systemic experience disproportionately suffered by women. By using a subframe of Gender-based violence, some of these articles referred to broader social trends such as the prevalence and/or patterns of sexual harassment in society, as seen in the following example from a news report. 
[headline] "Harassment: one in two Europeans has already gone through this!"

[Intro] "(...) One in two women living in Europe claims to have been victim of harassment, and one in five has been targeted in the last 12 months (...)" (Diário de Notícias, 14 November 2017).

Not all articles that frame sexual harassment as a systemic problem support the reasoning of gender-based violence. Although much less present, some texts use the subframe Problematic individual experiences, within which the issue is portrayed as a disturbing experience without linking it to the broader social and cultural context of unequal gender relations.

The overwhelming majority reader's comments framed the issue as a Non-issue $(60,48 \%)$, followed at a great distance by the Legal challenge frame $(15,62 \%)$, the Systemic deviant behaviour frame $(13,1 \%)$ and the Individual deviant behavior frame $(10,85 \%)$. Online discussions about street harassment bring weak attention to women's socially structural oppression with matter-of-fact statements based on gender stereotypes and myths. This is most evident in the context of the frame Individual deviant behaviour, which has a similar weight to the systemic frame in the reader' comments, despite being almost invisible in news media content and absent in the feminist media texts.

Individual deviant behaviour constructs street sexual harassment as an atypical and exceptional behaviour. Within this frame, harassment is recognized as an experience of some deviant individuals. From a feminist point of view, the problematic nature of this frame lies on the neoliberal ideology that puts full responsibility on individuals in terms of how they both cause and suffer the harm. Nuclear to what Rosalind Gill (2007) calls as a "postfeminist sensibility", this idea opens up spaces to see street harassment as an individual and avoidable experience. Both under the subframe Victim blaming - through which women cause or precipitate street harassment 
because of how they dress or behave -, and Equality in violence - that is, the belief that both male and female have the same agency and opportunity to harass -, these reasonings reproduce the dominant discourses on power and sexuality, as seen in these comments to mainstream news:

"If women did not walk around naked, this would not happen; it would be better if they walked in bikinis." (male reader, Correio da Manhã, 28 December 2015)

"Being a woman does not stop me from warning them. There are many [women] who offer themselves and then they complain." (female reader, Público, 8 August 2017)

Overall, these contradictory frames and ideas seem connected in such a way that where patriarchal gendered roles are challenged, we may expect a backlash against it.

\section{Backlash against the legal developments}

Data shows that street sexual harassment remained not only a "novel and untested legal issue", as Laura Nielsen $(2004,25)$ described it, but also a contested one. Indeed, the second most used frame in the sample, whether in the media texts or in the comments, is the Legal challenge. While different expressions and attitudes toward the law, the State, the harm, the offenders and the victims fit within this frame, the subframes positioned these attitudes in different ideological macrostructures. As shown in Figure 1, subframes corresponding to this generic frame vary across three meaningful ideas (Social reform, Culture backsliding and Technical uncertainty).

The Social reform subframe was mostly used by mainstream and alternative media texts, pointing out to how street harassment is a serious criminal harm. Differently, most reader's comments to mainstream media use the subframe Culture backsliding. For some, criminal law should not go "too far", especially when sexual freedom relates to female agency (Kearl 2015). For others, and because "honourable 
women have no ears" - a popular expression often repeated in readers' comments -, female power is equated with being able to avoid or ignore men's hostile remarks. Also, women's experiences of harassment are recurrently contested based on the argument that women also harass, and men enjoy it when they do so. This "common sense" appeals not only highlight supposedly gender-neutral principles but also overlooks women's struggles to have an actual voice in the public sphere, as seen in this comment: "Where is the equality that «everyone wants»? With so much law in favour of women it seems to be more of an imposition than a right. If a woman directed bad words to a man, is it a crime too? ... My grandmother used to say «honourable woman does not have ears». Who cares?" (female reader, Diário de Notícias, 28 December 2015).

As with the idea that "respectable women" are not harassed, explaining it as a practice of the lower classes, is also present in the frames of Legal reform as a Culture backsliding. Evoking the image of the construction worker catcalling women passing by, many comments ironize how these men lose not only their economic value, but also their freedom:

"Look at the Left going against the freedom of expression of the builder..." (male reader, Público, 30 August 2013)

Indeed, research shows how class, like other identity constructs, shapes the way harassing is seen and evaluated (Gardner 1995, Nielsen 2004). When harassment is understood as an act of the lower classes, Gardner $(1995,89)$ contends, “men's 'low' class and women's 'low' appearance" are used "as moral judgments to rationalize an offense." Under this framework, women will opportunistically decide which remarks are harmless, and which are not, depending on the status of its author:

"A piropo from the builder is a crime, but if it is from the owner of a Ferrari, they [women] open up to the world." (male reader, Correio da Manhã, 28 December 2015) 
The legal developments also raised suspicion and opposition because they were found too confusing in terms of what they cover. Although, as explained in previous sections of this article, "piropo" was far from being criminalized, readers discussed the legal change as if feminist's full demands had been met, causing cultural disruption. As such, comments line up with another dimension of postfeminist sensibility (Gill 2007), by both articulating and rejecting feminism in the same frame package.

The Legal challenge frame is mostly seen in Capazes readers' comments under the subframe Technical uncertainty, which highlights how legal clarification is missing, mostly given the contested nature of the "piropo". As one female reader commented:

"I agree that verbal harassment should be criminalized, but I also think we are confusing it with compliments. And both are not exclusive of men!" (Capazes, 26 December 2015)

Concerns around uncertainty in the application of law are also widely present in readers' comments to mainstream media. Some question whether a street comment should be considered a harm and under what circumstances:

"Once for all: is it or is not a crime to say 'you are sweet as corn'?" (male reader, Correio da Manhã, 28 December 2015)

This illustrates that, despite the fact that law only covers the proposals of "a sexual nature" - leaving out, for example, wolf whistles and catcalling -, much of the debate about the legal developments focused on the idea of the overall criminalization of catcalling. This caused inflamed accusations of "puritanism", stressing how regulation would be against free expression of thoughts, desire and seduction, producing a significant backlash against what was considered by some to be a product of "feminist radicalism." At times, this is done by simply reducing the law to a "no-brainer" and implausible issue, as seen in the words of a male reader: 
"When a stranger compliments you, is that a crime?" (male reader, Correio da Manhã, 28 December 2015)

\section{Depolitization of street sexual harassment}

As seen above, research tells us that street harassment is widespread ignored and trivialized - in Portugal (Dias, 2008; Magalhães, 2011) and elsewhere (Bowman 1993; Bates 2014; Johnson and Bennett 2015; Fileborn and Vera-Gray 2017). Consistent with this, we found a high degree of devaluation of the issue in Facebook, largely considering minor or unreasonable, i.e., a Non-issue. Although its presence in the mainstream media texts is residual, it is the leading frame of the online audiences $(60,48 \%)$, including the audiences of the feminist platform, despite the absence of this frame in its content.

Indeed, comments generated by news and opinion texts posted on Facebook by newspapers and by the feminist platform show little variations. The main subframe observed in both sites is Issue disqualification. Comments building this subframe are organized around the idea that unwanted sexual attention from strangers in public is an incoherent narrative, constructed by a puritan and reactionary discourse that contradicts everyday experiences. Comments, in this sense, are an important site of ideological accommodation.

This subframe is made up of different framing devices, offering three main reasons for disqualifying the issue. The first framing device is that women, while not admitting it, appreciate being catcalled and harassed. By drawing attention to the positive aspects of "piropo" as a verbal expression of flattery, appreciated by its receiver, comments re-naturalize the continuum of sexual violence (Kelly 2012) and everyday sexism (Bates 2014; Johnson and Bennett 2015). In highlighting the positive nature of street remarks, they accuse female complainants of not being "courteous" 
towards men's own courtesy and point to the contradictions underlining the claims to stop "men's expressive greetings" in public spaces. Both male and female readers often articulate this subframe. As for male, much female readers don't take piropo to be a harm. It should be distinguished, they contend, from the real "harmful" street intrusions:

"This discussion could only take place in Portugal... it feels so good to hear a piropo !!!" (female reader, Correio da Manhã, 8 September 2013)

This reaction to street remarks has long been seen by feminist research as a result of a mixed package of feelings, given the historical image of women in public spaces as "out of place" (Gardner 1980). Moreover, the apparently innocent separation between "piropos" and harms makes street harassment an exceptional experience, hindering its recognition as a daily practice. When readers' discussions centre on this perspective, several harmful experiences such as gross facial expressions, hand movements, catcalling are much more easily aligned with sexual performances, physical attraction and desire expressions.

The second main reasoning devices disqualifying street harassment allows the idea that controlling it means erasing important aspects of men and women' sexuality. Even those women who recognize being upset when receiving remarks in public spaces, highlight the benefits of men's erotic flirtation and its positive effects as a comic relief for sexual tension. In the words of a female reader:

“.... many dates ending up in marriage began with this kind of compliment or similar ones" (Correio da Manhã, 8 January 2018)

In some readers' comments, the "regulation of sexual desire" is problematic, because as they frame it, the law gives a death sentence to the typical repertoire of heterosexual affection and seduction experience. As a male reader claimed: 
"Is this a new effort to end the human species? Creating fear of each other? Without some harassment there will be no couples, since someone will have to take the first step." (Diário de Notícias, 14 November 2017.

The third key reasoning deep-seated in the Issue disqualification subframe is its reduced importance when compared with other matters affecting the nation. Here, street harassment is not an expression and enforcement of power, or part of a large repertoire of harassment actions that boys early learn (Gardner 1995). It is a "ridiculous" question and a "waste of time" and of the nation's efforts, which are instead needed to combat "really important" agendas:

"How it is possible that a compliment gives prison and these bankers who steal from people so many millions are free? What democracy is this?" (male reader, Diário de Notícias, 14 November 2017)

It was expected that feminist Capazes Facebook page would spark different reasoning devices. However, as with mainstream media texts, its readers contest the seriousness of street harassment.

Another way of framing street harassment as a Non-issue is by disqualifying the "claimants". Through this cognitive structure, it is not only activist's and other agent's ideas on regulation that are dismissed, but also the agents themselves. Arguments most often hinge on manifest parodying and stereotypical resources aiming to show their intellectual inferiority. The Claimants disqualification subframe is established by irony, contrast and metaphorical devices which insult the main sources and/or actors in the news and opinion columns.

This subframe rarely appears in comments to the feminist Facebook page and when observed it mostly shape the comments targeting the authors of the opinion texts, all signed by female activists with greater or lesser public notoriety. The following example is from a female reader, playing on the name of the feminist platform, which in Portuguese means "being able", connotating empowerment: 
“Will you girls be ABLE [Capazes] of not being silly?" (Capazes, 26 December 2015)

In some cases, verbal attacks come close to hate speech, with virulent, offensive and anti-female discourses, as the following example shows:

"Another mental retarded. Since when is a piropo sexual harassment? These people confuse everything. We should let rapists free and let them knock on their door." (Capazes, 26 December 2015)

\section{The online male gaze and the limited legal accomplishments}

Online posts and comments seem to be widely structured around normative identities. The female authorship lead in the case of feminist media texts and in the profiles of its readers' comments (163 female reader' comments against 30 from male readers). Most of the signed mainstream texts are also from women, while their readers are overwhelmingly male (1.104 against 445 female). However, there were no significant differences in how women and men framed the issue. In fact, discourse, regardless of its different functions, appears structured under the male gaze. As Claudia Alvares $(2018,660)$ argues, discussing the "online staging of femininity", the online dominance of male vision is not simply a reflection of offline cultural values. The "architecture of platform interfaces" favours profitable selves structured by gender power relations. Thus, more than simply commenting on a story or argument, readers engage in social media to discuss popular issues, public policy and even gender norms, in mostly reified gender identities. As with overall popular misogyny (Sarah-Weiser 2018), the belief that "piropo" is just an expression of "boys being boys" can be seen in this lens.

Also, despite the increasing awareness of gender inequalities expressed in news and opinion texts, street harassment found fierce opposition from the very first moment it captured the media attention, in September 2013, framed in several derogatory ways, 
as seen above. It was against the backdrop of this framing that the legal boundaries were adopted, with moderate ambition and falling short of the aim of the Istanbul Convention.

\section{Conclusion}

The analysis of 49 media texts and 1.759 readers' comments on street harassment legal developments shows a contradictory and complex set of frames building up this issue in social media. The backlash against the law that partly answered feminist claims was evident, but close analysis shows other cultural sensibilities and attitudes at play. The legal change was also met with postfeminist sensibilities (Gill 2007) and popular misogyny (Sarah-Weiser 2018). In particular, the issue

disqualification frame is based on the idea that feminist's agenda is no longer necessary: equality has been reached, namely on sexuality. "Piropo" is understood as a verbal expression of flattery, one that speaks directly to women's newly found feminism and sexual agency that no longer needs to be protected from men's sexual advances. What's more, many other issues deserve more pressing and urgent attention. In addition, popular misogyny becomes clearer for example in the claimant's disqualification subframe which organizes comments by networked irony and insult of main sources and/or actors in the news and opinion columns.

The social reform sub-frame did provide a means for feminist constructions of street harassment and the articulation of experiences of abuse and resistance, but the same legal change frame also developed into non feminist subframes which questioned the laws technical aspects and cultural effects.

In general, feminist concerns found their way into mainstream and alternative media texts, but they were mostly absent in reader's comments, which depicted it either as a systemic or an individual aberration, criticized its technical flaws and negative 
cultural impacts, and above all, dismissed it. Also, the analysis points out to gender bias, hate speech, sexism and different expressions of misogyny circulating overtly in online commenting spaces, making the recognition of street harassment as a harm linked to sexual violence and other types of systemic and institutional oppressions a rather arduous task. This suggests that the online discussions of street harassment legal developments were more infused with patriarchal cultural values than of feminist constructions of violence. This is consistent with the country's lasting views of gender relations and machismo that help to explain violence against women, resistance to change in the judicial system and in the society at large, but it is also a sign of new misogynist attitudes that find their way to networked social media, particularly as feminism becomes more widespread and more visible also in new and sometimes contradictory ways. The fact that the new version of the law did not fully reflect feminist's concerns is in itself a part of this latter phenomenon, by which political power responds to the increasing popularity of feminism, without fully acknowledging its demands.

Street harassment is virtually ubiquitous in the lives of adolescent girls and of women (Vera-Gray 2017). Consequently, women move through the world shaped by the experiential knowledge that "men's intrusion is inevitable, and women's bodies are the source', $(2017,143)$. This may help us to understand why any feminist attempt to resist and end harassment in public spaces meets such a huge backlash by the general public. And yet, this is also why it is important to understand why and how people reason and argue for or resist change, helping us to shift culture in effective ways.

Looking into media is also key to understand how law and culture are mutually constitutive forces that are continuously in interaction (Hajar Yazdiha 2017) and a proper consideration of this connection is a step forward to change harmful gender social norms. Understanding how people see and respond to street harassment in 
technologically mediated environments is equality important, given that they can offer spaces of resistance and struggle.

\section{References}

Aboim, Sofia, and Pedro Vasconcelos. 2012. Report on the Study on the role of men in gender equality in Portugal. Brussels: European Commission.

Alvares, Claudia. 2018. "Online staging of femininity: disciplining through public exposure in Brazilian social media". Feminist Media Studies 18(4): 657-674. doi: 10.1080/14680777.2018.1447336.

Anderson, Ashley, Sara Yeo, Dominique Brossard, Dietram Scheufele, and Michael Xenos. 2016. "Toxic Talk: How Online Incivility Can Undermine Perceptions of Media." International Journal of Public Opinion Research 30 (1):156-168. doi: 10.1093/ijpor/edw022 \%J International Journal of Public Opinion Research.

Bailey, Benjamin. 2017. "Greetings and compliments or street harassment? Competing evaluations of street remarks in a recorded collection." Discourse \& Society 28 (4):353-373. doi: 10.1177/0957926517702979.

Banet-Weiser, Sarah 2018. Empowered: Popular Feminism and Popular Misogyny, Durham, NC: Duke. University Press

Bates, Laura. 2014. Everyday sexism. London: Simon and Schuster.

Bowman, Cynthia Grant. 1993. "Street harassment and the informal ghettoization of women." Harvard Law Review 106:517-580. doi: 10.2307/1341656.

Creswell, John, and Vicki Plano Clark. 2017. Designing and Conducting Mixed Method Research. 3th ed. Thousand Oaks, CA: Sage.

Deirdre, Davis. 1994. "The Harm That Has No Name: Street Harassment, Embodiment, and African American Women." Review of https://escholarship.org/uc/item/83b9f21g. UCLA Women's Law Journal 4 (2).

Desborough, Karen. 2018. "The Global Anti-Street Harassment Movement: DigitallyEnabled Feminist Activism." In Mediating Misogyny: Gender, Technology, and Harassment, edited by Jacqueline Ryan Vickery and Tracy Everbach, 333-351. Cham: Springer International Publishing.

Dhillon, Megha, and Suparna Bakaya. 2014. "Street Harassment: A Qualitative Study of the Experiences of Young Women in Delhi." SAGE Open 4 (3):1-11. doi: $10.1177 / 2158244014543786$.

Dias, Isabel. "A violência contra as mulheres no trabalho: O caso do assédio sexual." Sociologia, Problemas e Práticas 57:11-23.

Dobash, Russell, and Emerson Dobash. 1992. Women, Violence and Social Change. London and New York: Routledge.

Entman, Robert. 1993. "Framing: Toward clarification of a fractured paradigm." Journal of Communication 43 (4):51-58. doi: 10.1111/j.14602466.1993.tb01304.x.

Entman, Robert. 2003. "Cascading Activation: Contesting the White House's Frame After 9/11." Political Communication 20 (4):415-432.

ERC. 2016. "Digital Media Portugal ERC 2015." Accessed September 20, 2018. http://www.erc.pt/download/YToyOntzOjg6ImZpY2hlaXJvljtzOjM4OiJtZWRpYS 9lc3R1ZG9zL29iamVjdG9fb2ZmbGluZS83OS4xLnBkZil7czo2OiJ0aXR1bG8iO3M6 
Mjc6ImRpZ2IOYWwtbWVkaWEtcG9ydHVnYWwtMjAxNSI7fQ==/digital-mediaportugal-2015

Fileborn, Bianca. 2014. "Online activism and street harassment: Digital justice or shouting into the ether?." Griffith Journal of Law and Human Dignity 2:32-51.

Fileborn, Bianca. 2016a. "Justice 2.0: Street harassment victims' use of social media and online activism as sites of informal justice." British Journal of Criminology 57 (6):1482-1501. doi: 10.1093/bjc/azw093.

Fileborn, Bianca. 2016b. Reclaiming the night-time economy: Unwanted sexual attention in pubs and clubs. London: Palgrave Macmillan.

Fileborn, Bianca. 2019. "Naming the Unspeakable Harm of Street Harassment: A Survey-Based Examination of Disclosure Practices." Violence Against Women 25 (2):223-248 doi: 10.1177/1077801218768709.

Fileborn, Bianca, and Fiona Vera-Gray. 2017. "II Want to be Able to Walk the Street Without Fear": Transforming Justice for Street Harassment." Feminist Legal Studies 25 (2):203-227. doi: 10.1007/s10691-017-9350-3.

FRA. 2014. Violence against women: An EU-wide survey main results. European Union Agency for Fundamental Rights. Accessed August 3, 2018. http://fra.europa.eu/sites/default/files/fra-2014-vaw-survey-mainresults_en.pdf

Gardner, Carol Brooks. 1980. "Passing By: Street Remarks, Address Rights, and the Urban Female." Sociological Inquiry 50 (3-4):328-356. doi: 10.1111/j.1475682X.1980.tb00026.x.

Gardner, Carol Brooks. 1995. Passing by: Gender and public harassment. Berkley: University of California Press.

Gill, Rosalind. 2007. "Postfeminist media culture: Elements of a sensibility." European Journal of Cultural Studies 10 (2):147-166.

Gill, Rosalind. 2016. "Post-postfeminism?: new feminist visibilities in postfeminist times." Feminist Media Studies 16(4): 610-630. doi: 10.1080/14680777.2016.1193293.

GREVIO. 2019. GREVIO Baseline Evaluation Report Portugal. Council of Europe. Acessed September 6, 2018. https://www.cig.gov.pt/wp content/uploads/2019/01/Relat\%C3\%B3rio-GREVIO.pdf.

Johnson, Molly, and Ebony Bennett. 2015. Everyday Sexism: Australian Women's Experiences of Street Harassment: Australia Institute.

Kearl, Holly. 2015. Stop global street harassment: Growing activism around the world. Santa Barbara, CA: Praeger.

Keller, Jessalynn, Kaitlynn Mendes, and Jessica Ringrose. 2018. "Speaking 'unspeakable things': documenting digital feminist responses to rape culture", Journal of Gender Studies 27(1):22-36. doi: 10.1080/09589236.2016.1211511.

Kelly, Liz. 1988. Surviving sexual violence. Oxford: Polity Press.

Kelly, Liz. 2012. "Preface. Standing the test of time? Reflections on the concept of the continuum of sexual violence'." In Handbook on Sexual Violence,, edited by Jennifer Brown \& Sandra Walklate. Oxon: Routledge.

Laniya, Olatokunbo Olukemi. 2005. "Street smut: Gender, media, and the legal power dynamics of street harassmentor "hey sexy" and other verbal ejaculations." Columbia Journal of Gender and Law 14:91-130. 
Lazar, Michelle. 2018. "Feminist critical discourse analysis." In The Routledge Handbook of Critical Discourse Studies, edited by John Flowerdew and John E. Richardson, 372-387. Oxon: Routledge.

Lisboa, Manuel, Zélia Barroso, Joana Patrício, and Alexandra Leandro. 2009. Violência e Género: Inquérito Nacional sobre a Violência Exercida contra Mulheres e Homens. Lisboa: Comissão para a Cidadania e Igualdade de Género.

Logan, Laura. 2015. "Street Harassment: Current and Promising Avenues for Researchers and Activists." Sociology Compass 9 (3):196-211. doi: 10.1111/soc4.12248.

Lourenço, Nelson, Manuel Lisboa, and Elza Pais. 1997. Violência contra as Mulheres. Lisboa: Comissão para a Igualdade e para os Direitos das Mulheres.

Magalhães, Mara, Lidia Marôpo and Inês Amaral. 2018. "Ativismo feminista no Facebook: uma análise comparada das páginas Não me Kahlo (Brasil) e Capazes (Portugal)." Mediapolis 7: 31-46.

Magalhães, Maria José. 2011. "Assédio sexual. Um problema de direitos humanos das mulheres." In Temas de vitimologia: Realidades emergentes na vitimação e respostas sociais, edited by Ana Sani, 103-113. Coimbra: Almedina.

Moernaut, Renée, Jelle Mast, and Luc Pauwels. 2018. "Framing Climate Change: A Multi-level Model." In Handbook of Climate Change Communication: Vol. 1. Climate Change Management, edited by E. Manolas W. L. Filho, A. M. Azul, U. M. Azeiteiro \& H. McGhie, 215-271. Cham: Springer.

Monteiro, Rosa, and Virgínia Ferreira. 2016. "Women's movements and the State in Portugal: a State feminism approach", Sociedade e Estado, 31, 2, 459-486

Nielsen, Laura Beth. 2004. License to Harass: Law, Hierarchy, and Offensive Public Speech. N.J: Princeton University Press.

O'Leary-Kelly, Anne M., Lynn Bowes-Sperry, Collette Arens Bates, and Emily R. Lean. 2009. "Sexual Harassment at Work: Moving Research Forward." Journal of Management 35: 503-536.

Sottomayor, Clara. 2015. "A Convenção de Istanbul e o novo paradigma da violência de género." ex æquo 31: 105-121.

Stanko, Elisabeth (1985). Intimate intrusions: Women's experience of male violence. London: Unwin Hyman.

UMAR. 2011. Rota dos feminismos contra o assédio sexual nos espaços públicos, na rua e no trabalho. Porto: Faculdade de Psicologia e Ciências da Educação da Universidade do Porto.

Van Gorp, Baldwin. 2005. "Where is the Frame?: Victims and Intruders in the Belgian Press Coverage of the Asylum Issue." European Journal of Communication 20 (4):484-507. doi: 10.1177/0267323105058253.

Van Gorp, Baldwin. 2007. "The Constructionist Approach to Framing: Bringing Culture Back In." Journal of Communication 57 (1):60-78. doi: 10.1111/j.00219916.2007.00329.x.

Van Gorp, Baldwin 2010. "Strategies to take subjectivity out of framing analysis." In Doing news framing analysis: Empirical and theoretical perspectives, edited by P. D’Angelo and J. A. Kuypers, 84-109. New York: Routledge. 
Vera-Gray, Fiona. 2016. "Men's stranger intrusions: Rethinking street harassment." Women's Studies International Forum 58:9-17. doi:

https://doi.org/10.1016/i.wsif.2016.04.001.

Vera-Gray, Fiona. 2017. Men's intrusion, women's embodiment: A critical analysis of street harassment. London: Routledge.

Vera-Gray, Fiona, and Bianca Fileborn. 2018. "Recognition and the Harms of 'Cheer Up'." Philosophical Journal of Conflict and Violence II (1):78-96.

Yazdiha, Hajar. 2017. "The relationality of law and culture: Dominant approaches and new directions for cultural sociologists." Sociology Compass 11 (12):e12545. doi: $10.1111 /$ soc4.12545. 